\title{
Prevalence of PfDHFR and PfDHPS Mutations Associated with Drug Resistance Among Pregnant Women Receiving IPTp-SP at Msambweni County Referral Hospital, Kwale County, Kenya
}

Stella Wanjiku Gikunju ( $\nabla$ stl.gikunju@gmail.com )

Kenya Medical Research Institute https://orcid.org/0000-0003-2709-2569

Eric L. Agola

Kenya Medical Research Institute

Raphael Omusebe Ondondo

Masinde Muliro University of Science and Technology

Johnson Kangethe Kinyua

Jomo Kenyatta University of Agriculture and Technology

Francis Kimani

Kenya Medical Research Institute

Angelle Desiree LaBeaud

Stanford University

Indu Malhotra

Case Western Reserve University

Charles H. King

Case Western Reserve University

Kelvin Thiong'o

Kenya Medical Research Institute

Francis Mutuku

Technical University of Mombasa

Research

Keywords: Plasmodium falciparum, drug resistance, SP, PfDHFR, PfDHPS, IPTp-SP, pregnant women, malaria

Posted Date: December 3rd, 2019

DOI: https://doi.org/10.21203/rs.2.17951/v1 
License: (c) (i) This work is licensed under a Creative Commons Attribution 4.0 International License. Read Full License

Version of Record: A version of this preprint was published at Malaria Journal on May 24th, 2020. See the published version at https://doi.org/10.1186/s12936-020-03263-z. 


\section{Abstract}

Background: Prevention and treatment of malaria during pregnancy is crucial in dealing with maternal mortality and adverse fetal outcomes. WHO's recommendation to treat all pregnant women with sulphadoxine-pyrimethamine (SP) through antenatal care structures was implemented in Kenya in the

year 1998 but concerns about its effectiveness in preventing malaria in pregnancy has arisen due to the spread of parasites resistant to SP. We aimed to determine the prevalence of SP resistance markers in Plasmodium falciparum parasites isolated from pregnant women seeking antenatal care at Msambweni County Referral Hospital, located in coastal Kenya, between the year 2013 and 2015.

Methods: This hospital-based study included 106 malaria positive whole blood samples for analysis of SP resistance markers within the PfDHFR gene (codons 51,59 \&108) and PfDHPS gene (codons 437 \& 540). The venous blood collected from all pregnant women was tested for malaria via light microscopy, then thereafter separated into plasma and red cells and stored in a -86区 freezer for further studies. Archived red blood cells were processed for molecular characterization of SP resistance markers within the PfDHFR gene and PfDHPS using real time PCR platform.

Results: All samples had at least one mutation in the genes associated with drug resistance; polymorphism prevalence of PfDHFR51I, 59R and $108 \mathrm{~N}$ was at $88.7 \%, 78.3 \%$ and $93.4 \%$, respectively, while PfDHPS polymorphism accounted for $94.3 \%$ and $91.5 \%$ at $437 \mathrm{G}$ and $540 \mathrm{~K}$, respectively. Quintuple mutations (at all the five codons) conferring total SP resistance had the highest prevalence of $86 \%$. Quadruple mutations were observed at a frequency of $10.4 \%$, and $24.5 \%$ had a heterogeneous outcome with both wildtype and mutant genotypes in the genes of interest.

Conclusion: The data suggest a high prevalence of Pf genetic variations conferring resistance to SP among pregnant women, which may explain reduced efficacy of IPTp treatment in Kenya. There is need for extensive SP resistance profiling in Kenya to inform IPTp drug choices for successful malaria prevention during pregnancy.

\section{Background}

Malaria is a significant public health problem in sub-Saharan Africa and remains a major contributor to morbidity and mortality in the African continent (1). The World Health Organization (WHO) has reported that Africa carries the highest burden of malaria: $92 \%$ of the malaria cases and $93 \%$ of malaria deaths worldwide (2). $99.7 \%$ of the cases are caused by Plasmodium falciparum with pregnant women being a particularly vulnerable population (3) especially those carrying first pregnancies at a young maternal age (4). Malaria in pregnancy contributes to maternal anemia leading to spontaneous abortion, stillbirth, premature birth and low birth weight (3). WHO has recommended an intermittent preventative treatment for pregnant women (IPTp) interventions using sulphadoxine-pyrimethamine (SP) drug, that Kenya implemented in the year 1998. Pregnant women then received at least two doses of SP given from the 
second trimester of pregnancy, which was later revised in 2009 to a monthly dose, to be administered during their antenatal clinic (ANC) visits (5).

IPTp prophylactic treatment has quickly been countered by the rise of $P$. falciparum (Pf) parasites resistant to SP, resulting in a loss in sensitivity to the SP drug. This resistance is attributed to single nucleotide polymorphism (SNP) mutations within the DHFR and DHPS genes that are target sites for the sulphadoxine and pyrimethamine active components of the drugs, which are most effective when working in synergy (6). In East Africa, the prevalence of these mutations is high, reaching near $100 \%$ in some regions $(7,8,9,10)$, thus raising concerns on the efficacy of the drug in preventing malaria in pregnancy.

The SP drug is still considered by practitioners to be effective in clearing the parasites in pregnant women, despite the high levels of $P f$ resistance that have been reported. To clarify this issue, the WHO has recommended that more studies be carried out to investigate the prevalence of $P f S P$ resistance molecular markers in parasites in the context of IPTp (11). Malaria is the leading cause of morbidity in Kwale County with a prevalence of $37.7 \%$ in comparison to other disease morbidities such as diarrhea, influenza, and respiratory diseases among others, which account for 4.6, 16.4, 5, and 3.1 per cent of disease burden in the county, respectively (12). This study investigated the prevalence of SP resistance molecular markers in parasites isolated from blood samples collected from the pregnant women receiving IPTp-SP treatment between 2013 and 2015 at Msambweni County Referral Hospital in Kwale County, Kenya. Since SP is the recommended drug for IPTp, continuous monitoring of its efficacy and for $P f$ resistance molecular markers is key in addressing malaria control among pregnant women. To our knowledge, this study is the first to assess resistance markers among pregnant women in coastal Kenya, contributing invaluable data on the rising prevalence of SP resistant $P$. falciparum among pregnant women in Kenya.

\section{Methods}

\section{Study area and sample collection}

This descriptive cross-sectional study involved pregnant women seeking antenatal care at the Msambweni County Referral Hospital between the year 2013 and 2015. There were a total of 763 pregnant women enrolled in the study who visited the antenatal clinic, and all were tested for malaria using light microscopy (13). Whatman filter paper was used to prepare dried blood spots (DBS) from the archived red blood cell samples which were then individually reserved in coded plastic bags with silica desiccant beads. The DBS were transported at room temperature to Centre for Biotechnology Research and Development (CBRD) within the Kenya Medical Research Institute (KEMRI) in Nairobi, Kenya for further molecular analysis.

\section{Molecular genotyping}


Genomic DNA was extracted from the DBS using a QIAamp DNA mini blood kit (Qiagen, Hilden, Germany), following the manufacturer's instructions. The malaria microscopy results were then confirmed for $P f$ using a Singleplex real-time qPCR assay carried out on an Applied Biosystems ${ }^{\text {TM }} 7500$ Fast Real-time PCR machine using a primer and probe set previously published (14) with each sample denatured at $95 \otimes C$ for 10 seconds and cycled 45 times with each cycle consisting of $95 \otimes C$ for 15 seconds and $55 \llbracket C$ for 60 seconds (15)

A modified Multiplex real time PCR assay described elsewhere (15) was performed with the same thermocyclic conditions using two hydrolysis probes for each codon. The wildtype strain was detected by a FAM labeled probe while the mutant strain was detected by a HEX labeled probe and each probe was tagged to a Black hole quencher. These probes differentiated single nucleotide polymorphisms (SNPS) within the PfDHFR gene and PfDHPS genes that are associated with SP resistance, targeting three SNPs within the PfDHFR gene at codon $51 /, 59 R$ and $108 N$ that confer resistance to pyrimethamine and two SNPs within the PfDHPS gene at codon $437 G$ and $540 E$ that confer resistance to sulphadoxine.

PCR was carried out in a $25 \mu \mathrm{l}$ final volume containing $12.5 \mu$ l of Agpath-ID ${ }^{\text {TM }}$ One-Step RT-PCR Kit, $5 \mu$ l of DNA template, forward and reverse primers at various concentrations shown in table 4 and both mutant and wildtype probes at a final concentration of $0.2 \mathrm{uM}$ (15) P. falciparum strain 3D7 and Dd2 were used as controls for wildtype and mutant strains respectively.

\section{Statistical analysis}

Characteristics of women were presented as means with standard deviations (SD) and as proportions. The prevalence of malaria parasites and mutations were expressed as a proportion with their respective $95 \%$ confidence interval $(95 \% \mathrm{Cl})$, while parasite load as median and its interquartile range (IQR). Comparisons of different factors for significant difference was done using t-test for quantitative variables while Chi square was used for binary variables, with a p-value of $<0.05$ considered significant. Statistical analysis was conducted using Stata version 12.0 software (StataCorp, 4905 Lakeway Drive, College Station, Texas 77845 USA).

\section{Results}

The majority of 763 pregnant women screened for malaria in this study were married (72\%) and had up to primary level of education (81\%). The mean ( \pm SD) age and gestation were $26( \pm 6.4)$ years and 23 ( \pm 5.2) weeks respectively. The median (IQR) number of visits with dispensed folic tablets and SP-IPTp were three (3-4) and three (2-4) respectively. The majority of women (98\%) had at least one dose of IPTp, while $88 \%$ received the WHO recommended IPTp doses $(\geq 2)$. Malaria parasites were detected in 135 pregnant women, yielding a prevalence of $17.7 \%$ (95\% Cl: 15.1-20.6). Young age, marital status and first pregnancy were significantly associated with malaria parasite infection (Table 1). SP-IPTp was not associated with decreased odds of malaria infection $(p=0.251)$. Of the 132 single women in the study, $32(24 \%)$ were infected with malaria compared to $88(16 \%)$ of married women. Therefore, single women 
(who were also likely to be younger) had increased odds of malaria infection compared to married women $(\mathrm{OR}=1.7 ; 95 \% \mathrm{Cl}: 1.1-2.7)$. Similarly, primigravidae were 1.7 times as likely to be detected with malaria parasites compared to multigravidae $(\mathrm{OR}=1.7 ; 95 \% \mathrm{Cl}: 1.1-2.5)$.

Placentas from malaria infected women had a significantly lower mean weight $(518.3 \pm 96.74 \mathrm{~g})$ compare to that of women negative for malaria $(550.3 \pm 98.86 \mathrm{~g}), \mathrm{p}<0.01$. However, malaria infection was not associated with mean placenta length, width or height (Table 1). Of the 568 women with hemoglobin levels, the mean $\mathrm{Hb}$ was $9.8( \pm 1.78) \mathrm{g} / \mathrm{dL}$ and $425(75 \%)$ were anemic $(\mathrm{Hb} \leq 11.0 \mathrm{~g} / \mathrm{dL})$. Among 277 women with anemia, $30(11 \%)$ had hookworm infection while only three of 99 women without anemia were infected. Therefore, hookworm infection was significantly associated with a near 4-fold increased odds of anemia among these pregnant women ( $\mathrm{OR}=3.9 ; 95 \% \mathrm{Cl}: 1.2-13.0)$, but not infection with malaria parasites $(\mathrm{p}=0.699)$. Women with hookworm infection had a significantly lower mean $\mathrm{Hb}$ $(9.3 \pm 1.38 \mathrm{~g} / \mathrm{dL})$ compared to those negative for hookworm $(10.0 \pm 1.78 \mathrm{~g} / \mathrm{dL}, \mathrm{p}<0.01)$.

Of the 135 pregnant women who tested positive for malaria, only 84 had archived blood samples available and these were included in $P$. falciparum genetic analysis. These women had a mean age: $23.7 \pm 6.14$ years and $32(38 \%)$ were primigravidae. The mean baseline $\mathrm{Hb}$ was $9.5( \pm 2.31) \mathrm{g} / \mathrm{dL}$ (Table 2). From these women, 106 of the blood samples (70 blood samples collected at first antenatal care visit and 36 collected at delivery) were all confirmed to contain $P$. falciparum parasites by real time PCR assay and were included in the mutation analyses. The median parasite load was 2760 (1200-7133) parasites $/ \mu \mathrm{L}$ of blood.

All samples were successfully genotyped yielding prevalences of PfDHFR gene and PfDHPSSNP mutations that ranged from 83-100\% (Table 3a). Of the 106 genotypes, $94(88.7 \%)$ harbored PfDHFR gene mutant allele $51 \mathrm{l}$, thus conferring a change in amino acid from asparagine $(\mathrm{N})$ to isoleucine $(\mathrm{I})$. Five samples $(4.7 \%)$ had a wildtype allele at codon $51 \mathrm{~N}$ and six samples $(5.6 \%)$ had mixed outcomes of both wild-type and mutant alleles at this codon (Table 3a). In 83 samples (78.3\%), mutant allele $59 R$ was detected resulting in expression of amino acid arginine (R) from cysteine (C). Two samples $(1.9 \%)$ had the wildtype allele $59 \mathrm{C}$ and 21 samples $(19.8 \%)$ had mixed outcomes with both wildtype and mutant alleles at codon 59. Almost all samples genotyped for the $108 \mathrm{~N}$ mutation at $94.3 \%$ with a SNP of $C$ to $T$ base pair leading to expression of asparagine $(\mathrm{N})$ from serine $(\mathrm{S})$. None of the 106 samples had the $108 \mathrm{~S}$ wildtype allele but six samples (5.6\%) had mixed outcomes of both wild-type and mutant alleles at this codon. The overall frequency of parasites with the PfDHFR triple mutantl ${ }_{51} \mathrm{R}_{59} \mathrm{~N}_{108}$ genotype was $87.4 \%$.

In estimating the prevalence of mutations observed in the PfDHPS gene, 94.3\% of the 106 samples harbored the mutant allele $437 \mathrm{G}$ thus expressing amino acid glycine $(\mathrm{G})$ from the wild-type alanine $(A)$. Two samples (1.9\%) exhibited the wildtype haplotype and four samples $(3.8 \%)$ had mixed outcome of both wild-type and mutant alleles. A polymorphism frequency of $91.5 \%$ was observed at codon 540 for all the samples genotyped with the mutant allele $540 E$ where glutamic acid (G) replaced the wild-type amino acid lysine (K). Five samples (4.7\%) exhibited wildtype haplotypes at codon 540 with only one sample 
having mixed outcome of both wild-type and mutant alleles. The overall frequency of mutations in the PfDHPS gene $\mathrm{G}_{437} \mathrm{E}_{540}$ was at $94.4 \%$.

In combination of PfDHFR and PfDHPS haplotypes (Table 3b), quintuple mutant genotype was the most prevalent $85.8 \%$ (91/106). Quadruple mutations were observed at $10.4 \%(11 / 106)$ where five of the samples had the wildtype allele at codon $51 \mathrm{~N}$ and two sample at codon $540 \mathrm{~K}$. Triple mutation was the least prevalent at 3.8\% (4/106) where mutant polymorphisms were in the PfDHFR gene while wildtype alleles were present in the PfDHPS gene. While two samples were wildtype at PfDHPS gene, no sample was fully wildtype at the PfDHFR gene. Clinically, 72 (86\%) of the 84 pregnant women had quintuple genotype (i.e. had pure or mixed mutations at all the five loci) suggesting total resistance to SP among these women. Only eight and four women had quadruple and triple genotypes, respectively.

\section{Discussion}

Malaria prevalence of $18 \%$ found in this study was higher than $10 \%$ and $13 \%$ observed among pregnant women in another Kenyan coastal region (16) and the lake region in Tanzania (17), respectively, but significantly lower than $31 \%$ documented in the Kenyan lake regions (16). Therefore, the high burden of malaria in pregnancy remains of public health concern. As observed in this study and elsewhere (18-20), younger women in their first pregnancy are at greatest risk of infection and should be targeted with preventive and early treatment interventions.

IPTp-SP is an important prophylactic therapy recommended for prevention of malaria in high endemic African regions to reduce morbidity/mortality among pregnant women and adverse pregnancy outcomes (2).The emerging high $P f$ resistance to the SP is likely to render IPTp-SP prophylactic intervention in effective. Similar to our findings, other studies have reported high prevalence $(78 \%-97 \%)$ of quintuple PfDHFR/PfDHPS haplotype mutations in western Kenya $(10,21)$. Studies elsewhere have documented quadruple mutations (65\%) in Equatorial Guinea (22) and $48 \%$ in DRC (23), and triple mutations (92\%) in Gabon (24) and $61-71 \%$ in Burkina Faso (25) as the most prevalent. Similar to India, where double mutation was the most prevalent $(26,27)$, a study in Brazil reported double mutation as most prevalent but did not find quintuple or quadruple mutations (28).

Findings from this study demonstrated very high prevalence of SNPs at the two important genes that confer SP resistance. The high prevalence of $89 \%$ observed at PfDHFR $51 /$ in this study was similarly to $(85 \%-100 \%)$ documented in western Kenya and elsewhere $(10,21-24,29)$, but contrary to the $21 \%$ reported in India (26). Although a study in DRC reported a conservative prevalence of $60 \%$ (23) at 59R, other studies found slightly higher prevalence $(87 \%-98 \%)$ at this codon $(10,21,22,24,26,29)$, compared to $78 \%$ demonstrated in this study. In agreement with our study, investigations elsewhere found a prevalence of $\geq 97 \%$ at $108 N(10,21-24,26,27,29)$. In contrast to average prevalence $(66 \%-68 \%)$ reported in India and Gabon $(24,26)$, prevalence of $>90 \%$ at PfDHPS437 $G$ was reported in this study, western Kenya and parts of central Africa. $(10,21-23,29)$. PfDHPS540E mutation is highly prevalent in Kenya $(10,21)$, but rare in several countries, which have reported a prevalence of only $0-5 \%(22-24,29)$. 
PfDHFR polymorphism at $51 /, 59 R$ and $108 N$ combined mutations of $89 \%$ observed in this study was similar to $89-97 \%$ documented in western Kenya among pregnant women(10,21). Proportion comparable to these have been reported elsewhere: $97 \%$ in Uganda (8); $87 \%$ in Equatorial Guinea (22); $98 \%$ in Cameroon (29), and $93 \%$ in Senegal (30). These frequencies were higher compared to $48 \%$ detected in DRC (23) and $54-74 \%$ in Burkina Faso $(25,31)$. The high frequency $(94 \%)$ of PfDHPS gene double mutation ( $437 \mathrm{G}$ and $540 \mathrm{E}$ ) reported in this study concurs with findings from other studies in East Africa that reported $90-99 \%$ and $99 \%$ in western Kenya $(10,21)$ and Uganda (8) respectively. However, double mutation in this gene are reportedly rare occurring with a prevalence of $4 \%$ in Equatorial Guinea (22), $1 \%$ in Burkina Faso (25), and $2 \%$ in DRC (23). An average mutation prevalence of $71.3 \%$ was seen at codon $540 E$ in the coastal regions of Tanzania which was low when compared to the country prevalence of $92.4 \%(9)$.

Several studies have demonstrated that the differing degrees of antimalarial drug resistance are dependent upon the number and combination of mutations present (32). The PfDHFR/PfDHPS quintuple mutant, in either mixed or pure form, is the most clinically relevant molecular marker for SP resistance. In the East African region, the prevalence of molecular markers of SP resistance has been increasing since the emergence of the first resistance-conferring mutations in the 1950s (9). Therefore, continuous molecular surveillance will allow early detection of drug resistance susceptibility and high mutation prevalence within the PfDHFR and PfDHPS gene of the $P f$ parasite that reduce SP drug effectiveness as a prophylactic treatment for malaria in pregnancy (25). These finding show that there is high prevalence of PfDHFR/PfDHPS haplotype mutations believed to confer resistance to SP, the drug of choice for malaria prophylactic treatment in pregnant women. Our data aligned with findings in other parts of Kenya and other tropical regions in defining high prevalence of SP resistance markers within circulating $P f$ isolates.

\section{Conclusion}

Results from this study suggest that coastal Kenya has high prevalence of PfDHFR triple mutation and PfDHPS double mutation that could potentially undermine the efficacy of SP drug for prophylactic treatment among pregnant women. Despite growing evidence of high prevalence of genetic mutation within the PfDHFR and PfDHPS genes associated with SP drug resistance, it is still the recommended drug for IPTp in Kenya and sub-Saharan Africa regions which carry a disproportionately high burden of malaria (2). There is therefore urgent need for development of safe and more effective malaria drugs for prophylactic treatment of malaria in pregnancy. Continuous monitoring and treatment of malaria infection among pregnant women is necessary to avert malaria-related adverse pregnancy outcomes.

\section{Declaration}

\section{ETHICAL APPROVAL}

Written informed consent was obtained from each study participant before study participation. The ethical approvals were granted by the Kenyatta National Hospital Ethical Review committee; 
\#P85/03/2013, the Institutional Review Board for Human Studies at University of Cleveland Case Medical Center; \#01-13-13 and the KEMRI Scientific Ethics and Review Committee (SERU); \#SSC3134.

\section{CONSENT FOR PUBLICATION}

Not applicable.

\section{AVAILABILITY OF DATA AND MATERIALS}

The dataset analyzed for this study is available from the corresponding author on reasonable request.

\section{COMPETING INTERESTS}

Authors declare no conflict of interest.

\section{FUNDING}

The author of this publication received research support from Bill \& Melinda Gates Foundation that supported the primary study conducted at Msambweni Referral County Hospital with an equipment loan from the Centers for Disease Control and Prevention-Kenya.

\section{AUTHOR'S CONTRIBUTION}

SWG, KF, ALE, KJ, IM, ADL, CHK and MF designed the study; SWG and KT performed all laboratory analysis; ROO analyzed and presented the data; SWG and ROO drafted the paper, all authors reviewed and approved the final manuscript.

\section{ACKOWLEDGEMENTS}

We would like to acknowledge the study participants, study team and institutional support from JKUAT and KEMRI. Special thanks to Dr. Bonventure Juma, Victor Omballa and Caroline Apondi for sharing their molecular technical expertise. Protus Omondi, Angela Aringo, Timothy Chege and Jael Sagina for their technical support in the Laboratory. The maternal-infant cohort study that supplied the anonymized test materials was funded by the Bill \& Melinda Gates Foundation (OPP 1066865).

\section{References}

1. Yaya S, Uthman O, Amouzou A, Bishwajit G, Yaya S, Uthman OA, et al. Use of Intermittent Preventive Treatment among Pregnant Women in Sub-Saharan Africa: Evidence from Malaria Indicator Surveys. 
Trop Med Infect Dis [Internet]. 2018 Feb 11 [cited 2019 Jun 8];3(1):18. Available from: http://www.mdpi.com/2414-6366/3/1/18

2. World Health Organization. World Malaria Report 2018 Isbn 978924156565 3. WHO. 2018;

3. WHO I Lives at risk: malaria in pregnancy. WHO [Internet]. 2013 [cited 2019 Jun 8]; Available from: https://www.who.int/features/2003/04b/en/

4. Desai M, Gutman J, Taylor SM, Wiegand RE, Khairallah C, Kayentao K, et al. Impact of sulfadoxinepyrimethamine resistance on effectiveness of intermittent preventive therapy for Malaria in pregnancy at clearing infections and preventing low birth weight. Clin Infect Dis. 2016;

5. National Malaria Control Programme (NMCP) Kenya National Bureau of, Statistics (KNBS) and II. Kenya - Malaria Indicator Survey 2015. Nairobi; Rockv NMCP, KNBS, ICF Int [Internet]. 2016;165. Available from: http://microdata.worldbank.org/index.php/catalog/2570

6. Bloland PB. Drug resistance in malaria. A Background Document for the WHO Global Strategy for Containment of Antimicrobisl Resistance. 2001;12.

7. Braun V, Rempis E, Schnack A, Decker S, Rubaihayo J, Tumwesigye NM, et al. Lack of effect of intermittent preventive treatment for malaria in pregnancy and intense drug resistance in western Uganda. Malar J [Internet]. 2015 Dec 26 [cited 2019 Jun 8];14(1):372. Available from: http://www.malariajournal.com/content/14/1/372

8. Mbonye AK, Birungi J, Yanow SK, Shokoples S, Malamba S, Alifrangis M, et al. Prevalence of Plasmodium falciparum Resistance Markers to Sulfadoxine-Pyrimethamine among Pregnant Women Receiving Intermittent Preventive Treatment for Malaria in Uganda. Antimicrob Agents Chemother. 2015 Sep;59(9):5475-82.

9. Kavishe RA, Kaaya RD, Nag S, Krogsgaard C, Notland JG, Kavishe AA, et al. Molecular monitoring of Plasmodium falciparum super-resistance to sulfadoxine-pyrimethamine in Tanzania. Malar J. 2016;15(1):1-8.

10. Iriemenam NC, Shah M, Gatei W, van Eijk AM, Ayisi J, Kariuki S, et al. Temporal trends of sulphadoxine-pyrimethamine (SP) drug-resistance molecular markers in Plasmodium falciparum parasites from pregnant women in western Kenya. Malar J [Internet]. 2012 Apr 27 [cited 2019 Jun 4];11(1):134. Available from: http://malariajournal.biomedcentral.com/articles/10.1186/14752875-11-134

11. Health A. WHO policy brief for the implementation of intermittent preventive treatment of malaria in pregnancy April 2013 ( revised January 2014). 2014;(October 2012).

12. COUNTY GOVERNMENT OF KWALE FIRST COUNTY INTEGRATED DEVELOPMENT PLAN 2013 Towards a Globally Competitive and Prosperous Nation.

13. McKittrick ND, Malhotra IJ, Vu DM, Boothroyd DB, Lee J, Krystosik AR, et al. Parasitic infections during pregnancy need not affect infant antibody responses to early vaccination against streptococcus pneumoniae, diphtheria, or haemophilus influenzae type B. PLoS Negl Trop Dis. 2019;

14. Liu J, Ochieng C, Wiersma S, Ströher U, Towner JS, Whitmer S, et al. Development of a TaqMan array card for acute-febrile-illness outbreak investigation and surveillance of emerging pathogens, 
including ebola virus. J Clin Microbiol. 2016;

15. Alker AP, Mwapasa V, Meshnick SR. Rapid real-time PCR genotyping of mutations associated with sulfadoxine-pyrimethamine resistance in Plasmodium falciparum. Antimicrob Agents Chemother [Internet]. 2004 Aug 1 [cited 2019 Jun 8];48(8):2924-9. Available from:

http://www.ncbi.nlm.nih.gov/pubmed/15273102

16. Githinji S, Noor AM, Malinga J, Macharia PM, Kiptui R, Omar A, et al. A national health facility survey of malaria infection among febrile patients in Kenya, 2014. Vol. 15, Malaria Journal. BioMed Central Ltd.; 2016.

17. Willilo RA, Molteni F, Mandike R, Mugalura FE, Mutafungwa A, Thadeo A, et al. Pregnant women and infants as sentinel populations to monitor prevalence of malaria: Results of pilot study in Lake Zone of Tanzania. Malar J. 2016;

18. van Eijk AM, Hill J, Noor AM, Snow RW, ter Kuile FO. Prevalence of malaria infection in pregnant women compared with children for tracking malaria transmission in sub-Saharan Africa: A systematic review and meta-analysis. Lancet Glob Heal. 2015;

19. Fried M, Duffy PE. Malaria during pregnancy. Cold Spring Harb Perspect Med. 2017;

20. Duffy PE, Desowitz RS. Pregnancy malaria throughout history: dangerous labors. In: Malaria in pregnancy: deadly parasite, susceptible host. 2001.

21. Hemming-Schroeder E, Umukoro E, Lo E, Fung B, Tomás-Domingo P, Zhou G, et al. Impacts of antimalarial drugs on plasmodium falciparum drug resistance markers, Western Kenya, 2003-2015. Am J Trop Med Hyg. 2018;98(3):692-9.

22. Jiang T, Chen J, Fu H, Wu K, Yao Y, Urbano J, et al. High prevalence of Pfdhfr-Pfdhps quadruple mutations associated with sulfadoxine-pyrimethamine resistance in Plasmodium falciparum isolates from Bioko Island, Equatorial Guinea. Malar J [Internet]. 2019;1-8. Available from: https://doi.org/10.1186/s12936-019-2734-x

23. Ruh E, Bateko JP, Imir T, Taylan-Ozkan A. Molecular identification of sulfadoxine-pyrimethamine resistance in malaria infected women who received intermittent preventive treatment in the Democratic Republic of Congo. Malar J [Internet]. 2018;17(1):1-7. Available from: https://doi.org/10.1186/s12936-017-2160-x

24. Ndong Ngomo JM, Mawili-Mboumba DP, M'bondoukwe NP, Nikiéma Ndong Ella R, Bouyou Akotet MK. Increased Prevalence of Mutant Allele Pfdhps 437G and Pfdhfr Triple Mutation in Plasmodium falciparum Isolates from a Rural Area of Gabon, Three Years after the Change of Malaria Treatment Policy. Malar Res Treat. 2016;

25. Ruizendaal E, Tahita MC, Traoré-Coulibaly M, Tinto H, Schallig HDFH, Mens PF. Presence of quintuple dhfr N51, C59, S108-dhps A437, K540 mutations in Plasmodium falciparum isolates from pregnant women and the general population in Nanoro, Burkina Faso. Mol Biochem Parasitol [Internet]. 2017 Oct 1 [cited 2019 Jun 8];217:13-5. Available from: https://www.sciencedirect.com/science/article/pii/S0166685117300889 
26. Mohapatra PK, Sarma DK, Prakash A, Bora K, Ahmed MA, Sarma B, et al. Molecular evidence of increased resistance to anti-folate drugs in Plasmodium falciparumin North-east India: A signal for potential failure of artemisinin plus sulphadoxine-pyrimethamine combination therapy. PLoS One. 2014;

27. Srivastava P, Ratha J, Shah NK, Mishra N, Anvikar AR, Sharma SK, et al. A clinical and molecular study of artesunate + sulphadoxine-pyrimethamine in three districts of central and eastern India. Malar J. 2013;

28. Gomes LR, Lavigne A, Brasil P, Peterka CL, Ménard D, Daniel-Ribeiro CT, et al. Lack of quadruple and quintuple mutant alleles associated with sulfadoxine-pyrimethamine resistance in plasmodium vivax isolates from Brazilian endemic areas. Mem Inst Oswaldo Cruz. 2019;

29. Chauvin P, Menard S, Iriart X, Nsango SE, Tchioffo MT, Abate L, et al. Prevalence of Plasmodium falciparum parasites resistant to sulfadoxine/pyrimethamine in pregnant women in Yaoundé Cameroon: Emergence of highly resistant pfdhfr/pfdhps alleles. J Antimicrob Chemother. 2015;

30. Ndiaye D, Dieye B, Ndiaye YD, Tyne D Van, Daniels R, Bei AK, et al. Polymorphism in $\mathrm{dhfr} / \mathrm{dhps}$ genes, parasite density and ex vivo response to pyrimethamine in plasmodium falciparum malaria parasites in thies, senegal. Int J Parasitol Drugs Drug Resist. 2013;

31. Geiger C, Compaore G, Coulibaly B, Sie A, Dittmer M, Sanchez C, et al. Substantial increase in mutations in the genes pfdhfr and pfdhps puts sulphadoxine-pyrimethamine-based intermittent preventive treatment for malaria at risk in Burkina Faso. Trop Med Int Heal. 2014;

32. Mbaisi A, Liyala P, Eyase F, Achilla R, Akala H, Wangui J, et al. Drug susceptibility and genetic evaluation of Plasmodium falciparum isolates obtained in four distinct geographical regions of Kenya. Antimicrob Agents Chemother [Internet]. 2004 Sep 1 [cited 2019 Jun 8];48(9):3598-601. Available from: http://www.ncbi.nlm.nih.gov/pubmed/15328137

\section{Tables}


Table 1: Characteristics of pregnant women screened for malaria parasites between 2013 -2015 at Msambweni County Referral Hospital in Mombasa, Kenya

\begin{tabular}{|c|c|c|c|}
\hline $\begin{array}{l}\text { Characteristic } \\
\text { Age (mean; SD) years }\end{array}$ & $\begin{array}{l}\text { Negative (N=628) } \\
26.4(6.31)\end{array}$ & $\begin{array}{l}\text { Positive (N=135) } \\
24.4(6.34)\end{array}$ & $\begin{array}{l}\text { p value } \\
<0.001\end{array}$ \\
\hline \multicolumn{4}{|l|}{ Marital status (n, \%) } \\
\hline Single & $100(16 \%)$ & $32(24 \%)$ & 0.030 \\
\hline Married & $468(75 \%)$ & $88(65)$ & 0.027 \\
\hline Cohabiting & $51(8 \%)$ & $14(10)$ & 0.400 \\
\hline Divorced/separated & $9(1 \%)$ & $1(1 \%)$ & 0.521 \\
\hline \multicolumn{4}{|l|}{ Education $(\mathrm{n}, \%)$} \\
\hline None to Lower primary & $149(24 \%)$ & $41(30 \%)$ & 0.105 \\
\hline Upper Primary & $358(57 \%)$ & $72(53 \%)$ & 0.435 \\
\hline Secondary & $121(19 \%)$ & $22(16 \%)$ & 0.422 \\
\hline \multicolumn{4}{|l|}{ Occupation (n, \%) } \\
\hline Housewife/Not working & $541(86 \%)$ & $123(91 \%)$ & 0.862 \\
\hline Employed (formal or self) & $87(14 \%)$ & $12(9 \%)$ & 0.120 \\
\hline \multicolumn{4}{|l|}{ Monthly household expenditure (n, \%) } \\
\hline$<5000$ & $45(7 \%)$ & $12(9 \%)$ & 0.490 \\
\hline$\geq 5000$ & $583(93 \%)$ & $123(91 \%)$ & 0.490 \\
\hline \multicolumn{4}{|l|}{ Bed net (n, \%) } \\
\hline Yes & $596(95 \%)$ & $122(90 \%)$ & 0.043 \\
\hline No & $32(5 \%)$ & $13(10 \%)$ & 0.043 \\
\hline \multicolumn{4}{|l|}{ First Pregnancy $(n, \%)$} \\
\hline Yes & $144(23 \%)$ & $45(33 \%)$ & 0.011 \\
\hline No & $484(77 \%)$ & $90(67 \%)$ & 0.011 \\
\hline Gestation in weeks (mean, SD) & $23.3(5.17)$ & $22.1(5.21)$ & 0.017 \\
\hline Number of visits of Folic use (mean, SD) & $3.4(1.39)$ & $3.8(1.36)$ & 0.007 \\
\hline Number of visits with SP use (mean, SD) & $3.2(1.39)$ & 3.5 (1.39) & 0.015 \\
\hline HB g/dl (mean, SD) & $9.8(1.82)$ & $9.9(1.57)$ & 0.472 \\
\hline Parasite load/ $\mathrm{LL}$ of blood (median; IQR) & NA & $2400(960-7200)$ & \\
\hline Placenta (mean, SD) & Mean & & \\
\hline Weight (g) & $550.3(98.86)$ & $518.3(96.74)$ & 0.002 \\
\hline Length (cm) & $19.3(1.77)$ & $19.1(1.66)$ & 0.162 \\
\hline Width $(\mathrm{cm})$ & $17.3(1.91)$ & $17.1(1.80)$ & 0.178 \\
\hline Height $(\mathrm{cm})$ & $2.2(0.38)$ & $2.2(0.33)$ & 0.826 \\
\hline
\end{tabular}


Table 2: Characteristics of 84 pregnant women from whom Plasmodium falciparum isolates were recovered for genetic analysis

\section{Characteristic}

Age in years (mean; SD)

Marital status:

Single

Married

Cohabiting

Divorced

Education:

None to Lower primary school

Upper Primary school

Secondary school

Occupation:

\section{Housewife/Not working}

Employed

Monthly household expenditure (KShs.):

$$
\begin{aligned}
& <5000 \\
& \geq 5000
\end{aligned}
$$

Bed net use:

$$
\text { Yes }
$$

No

First pregnancy?

Yes

No

Gestation in weeks (mean, SD)

Number of Visits of Folic acid use (mean, SD)

Number of Visits of SP use (mean, SD)

$\mathrm{Hb}$ g/dL (mean, SD)

Parasite load/pL of blood (median; IQR)
Mean, Median or Proportion

23.7 (6.14)

$19(23 \%)$

$53(63 \%)$

$11(13 \%)$

$1(1 \%)$
$24(29 \%)$

$48(57 \%)$

$12(14 \%)$

79 (94\%)

$5(6 \%)$

$61(73 \%)$

$23(27 \%)$

76 (90\%)

$8(10 \%)$

$32(38 \%)$

$52(62 \%)$

$22.0(5.19)$

3.7 (1.40)

$3.5(1.43)$

$9.5(2.31)$

2760 (1200-7133) 
Table 3: Genetic analysis of Pfdhfr and Pfdhps SNPs in Plasmodium falciparum isolates from Mombasa, Kenya

\begin{tabular}{|c|c|c|c|}
\hline \multicolumn{4}{|c|}{ a) Prevalence of Pfdhfr and Pfdhps SNPs in isolated $P$. falciparum malaria parasites } \\
\hline $\begin{array}{c}\text { SNP } \\
(\mathrm{N}=106)\end{array}$ & $\begin{array}{l}\text { Mutant Type } \\
\text { n (\%, 95\% CI) }\end{array}$ & $\begin{array}{l}\text { Mixed Type } \\
\mathrm{n}(\%, 95 \% \mathrm{CI})\end{array}$ & $\begin{array}{l}\text { Wild Type } \\
\text { n (\%, 95\% CI) }\end{array}$ \\
\hline 51 & $\begin{array}{l}94(88.68,80.69 \text { to } \\
93.76)\end{array}$ & $6(5.66,2.32$ to 12.41$)$ & $\begin{array}{l}5(4.72,1.75 \text { to } \\
11.19)\end{array}$ \\
\hline 59 & $\begin{array}{l}83(78.30,69.03 \text { to } \\
85.48)\end{array}$ & $\begin{array}{l}21(19.81,12.95 \text { to } \\
28.91)\end{array}$ & $2(1.89,0.33$ to 7.32$)$ \\
\hline 108 & $\begin{array}{l}99(93.40,86.40 \text { to } \\
97.08)\end{array}$ & $6(5.66,2.32$ to 12.41$)$ & $0(0.00)$ \\
\hline 437 & $\begin{array}{l}100(94.34,87.59 \text { to } \\
97.68)\end{array}$ & $4(3.77,1.21$ to 9.94$)$ & $2(1.89,0.33$ to 7.32$)$ \\
\hline 540 & $\begin{array}{l}97(91.51,84.07 \text { to } \\
95.80)\end{array}$ & $1(0.64,0.05$ to 5.90$)$ & $\begin{array}{l}5(4.72,1.75 \text { to } \\
11.19)\end{array}$ \\
\hline
\end{tabular}

b) Different combinations of PfDHFR/PfDHPS haplotype mutations

\begin{tabular}{cccccc} 
& & Mutants only & \multicolumn{2}{c}{ Mutants + Mixed } \\
\cline { 4 - 6 } Genotype & $\mathrm{n}$ & $\%$ & $\mathrm{n}$ & $\%$ \\
Double & 7 & 6.6 & 0 & 0 \\
\hline Triple & 7 & 6.6 & 4 & 11 \\
\hline Quadruple & 22 & 20.8 & 91 & 8.8 \\
\hline Quintuple & 70 & 66 & & 85.8 \\
\hline
\end{tabular}


Table 4: Primer information

\begin{tabular}{|c|c|c|c|c|c|c|}
\hline No. & Primer Name & \multicolumn{3}{|c|}{ Sequence } & Amount & Modified \\
\hline 1 & P.falc F & 5 & GCTCTTTCTTGATTTCTTGGATG & 3 & $0.3 \mathrm{uM}$ & No \\
\hline 2 & P.falc R & 5 & AGCAGGTTAAGATCTCGTTCG & 3 & $0.3 \mathrm{uM}$ & No \\
\hline 3 & P.falc P & 5 & CACGAACTAAAAACGGCCAT & 3 & $0.2 \mathrm{uM}$ & FAM-BHQ1 \\
\hline 4 & DHFR-51 F & 5 & TGAGGTTTTTAATAACTACACATTTAGAGGTCT & 3 & $0.3 \mathrm{uM}$ & No \\
\hline 5 & DHFR-51 R & 5 & TATCATTTACATTATCCACAGTTTCTTTGTT & 3 & $0.3 \mathrm{uM}$ & No \\
\hline 6 & $\begin{array}{l}\text { DHFR-51 } \\
\text { WTP }\end{array}$ & 5 & AATGTAATTCCCTAGATATG & 3 & $0.2 \mathrm{uM}$ & FAM-BHQ1 \\
\hline 7 & DHFR-51 MP & 5 & AAATGTATTTCCCTAGATATG & 3 & $0.2 \mathrm{uM}$ & HEX-BHQ1 \\
\hline 8 & DHFR-59 F & 5 & Same primer sequence as DHFR - 51F & 3 & $0.3 \mathrm{uM}$ & No \\
\hline 9 & DHFR-59 R & 5 & Same primer sequence as DHFR - 51F & 3 & $0.5 \mathrm{uM}$ & No \\
\hline 10 & $\begin{array}{c}\text { DHFR-59 } \\
\text { WTP } \\
\end{array}$ & 5 & AATATTTTTGTGCAGTTACA & 3 & $0.2 \mathrm{uM}$ & FAM-BHQ1 \\
\hline 11 & DHFR-59 MP & 5 & TGAAATATTTTCGTGCAGTTA & 3 & $0.2 \mathrm{uM}$ & HEX-BHQ1 \\
\hline 12 & DHFR-108 F & 5 & TGGATAATGTAAATGATATGCCTAATTCTAA & 3 & $0.3 \mathrm{uM}$ & No \\
\hline 13 & DHFR-108 R & 5 & AATCTTCTTTTTTTAAGGTTCTAGACAATATAACA & 3 & $0.3 \mathrm{uM}$ & No \\
\hline 14 & $\begin{array}{c}\text { DHFR-108 } \\
\text { WTP }\end{array}$ & 5 & AGAACAAGCTGGGAAA & 3 & $0.2 \mathrm{uM}$ & FAM-BHQ1 \\
\hline 15 & $\begin{array}{c}\text { DHFR-108 } \\
\text { MP }\end{array}$ & 5 & AGAACAAACTGGGAAAG & 3 & $0.2 \mathrm{uM}$ & HEX-BHQ1 \\
\hline 16 & DHPS-437 F & 5 & TGAAATGATAAATGAAGGTGCTAGTGT & 3 & 0.9uM & No \\
\hline 17 & DHPS-437 R & 5 & AATACAGGTACTACTAAATCTCTTTCACTAATTTTT & 3 & 0.9uM & No \\
\hline 18 & $\begin{array}{c}\text { DHPS-437 } \\
\text { WTP }\end{array}$ & 5 & AGAATCCTCTGCTCCT & 3 & $0.2 \mathrm{uM}$ & FAM-BHQ1 \\
\hline 19 & $\begin{array}{c}\text { DHPS-437 } \\
\text { MP }\end{array}$ & 5 & AATCCTCTGGTCCTTT & 3 & $0.2 \mathrm{uM}$ & HEX-BHQ1 \\
\hline 20 & DHPS-540 F & 5 & AATGCATAAAAGAGGAAATCCACAT & 3 & $0.3 \mathrm{uM}$ & No \\
\hline 21 & DHPS-540 R & 5 & TCGCAAATCCTAATCCAATATCAA & 3 & $0.3 \mathrm{uM}$ & No \\
\hline 22 & $\begin{array}{c}\text { DHPS-540 } \\
\text { WTP }\end{array}$ & 5 & CAATGGATAAACTAACAAA & 3 & $0.2 \mathrm{uM}$ & FAM-BHQ1 \\
\hline
\end{tabular}




\begin{tabular}{|c|c|c|c|c|c|c|}
23 & $\begin{array}{c}\text { DHPS-540 } \\
\text { MP }\end{array}$ & 5 & AATGGATGAACTAACAAA & 3 & 0.2 uM & HEX-BHQ1 \\
\hline
\end{tabular}

